\title{
OUTCOMES-BASED EDUCATION: IS IT RIGHT FOR SOCIAL WORK?
}

\section{Barbara Simpson}

\section{INTRODUCTION}

Outcomes-based education (OBE) has been very much in the news lately. Graeme Bloch's book The toxic mix: what's wrong with SA schools and how to fix it (2009) has received widespread coverage in the press, as have the results of the National Benching Tests Project (HESA, 2009), which demonstrated that a large number of entry-level students at tertiary institutions were not sufficiently competent in academic literacy, quantitative literacy or mathematics to succeed at university without substantial additional help. There are many complex reasons for the problems in the South African education system, but the suitability outcomes-based education to address the education challenges in South Africa has been seriously questioned.

Social work education in South Africa has immersed itself wholeheartedly in the OBE rhetoric, given the regulations on how the Bachelor of Social Work degree is offered. It has a plethora of exit-level outcomes (ELOs), associated assessment criteria (AAC) and critical cross-field outcomes (CCFOs). This move towards outcomes-based education has been largely uncontested by social work educators, with only two articles being published in the South African social work journals - one by Lombard, Grobbelaar and Pruis in 2003, which uncritically described the process of registering the BSW, and one by Bozalek in 2009, which focused on outcomes-based assessment and provided a critical discussion of both the advantages and disadvantages.

The purpose of this article is to stimulate further debate and discussion about the BSW. I begin by describing the context in which the BSW was developed, and specifically the underlying assumptions that led to the establishment of the South African Qualifications Authority (SAQA) and the National Qualifications Framework (NQF). I then go on to describe outcomesbased education and demonstrate numerous ways in which it is problematic for social work education. I take the view that OBE is flawed and that the emphasis on outcomes and specific assessment criteria in the BSW is not right for social work as a discipline within the academy or as a profession.

\section{BACKGROUND: SAQA, NQF AND THE BSW}

The South African Qualifications Act, No. 58 of 1995 was intended as the means of addressing the serious inequalities of the apartheid educational system. The way in which this was to be done was through the establishment of a National Qualifications Framework (NQF) and an outcomes-based educational system with an explicit focus on what has been learned as measured against socially agreed standards (Chisholm, 2007). It was envisaged that the NQF would provide a coherent approach to qualifications and thus bring education and training together, to boost skill and productivity levels, and to address issues of equity and social justice (Ensor, 2003; Lugg, n.d.).

According to the SA Qualifications Act, No. 58 of 1995, the objectives of the NQF were to:

- create an integrated national framework for learning achievements;

- facilitate access to, and mobility and progression within, education, training and career paths; 
- enhance the quality of education, training and skills development;

- accelerate the redress of past unfair discrimination in education, training and employment opportunities; and thereby

- contribute to the full personal development of each learner and the social and economic development of the nation at large.

This was reviewed in 2001 and has now been replaced by the NQF Act, No. 67 of 2008. While there have been a number of changes, the objectives remain essentially the same, with the emphasis on an integrated framework, enhancing quality of education and training, facilitating access and redress of past inequalities.

Support for the establishment of a National Qualifications Framework was rooted in the antiapartheid struggle, particularly in the labour movement (Allais, 2007). The idea that no one form of knowledge was privileged and that an NQF could blur the traditional boundaries between education and training was very appealing in a context in which the democratisation of education was a paramount objective. The underlying assumption, as Ensor (2003) points out, was that all forms of knowledge are commensurable and that there is no fundamental difference between education and training, between academic and everyday knowledge, and between different disciplines. All can be reduced to specific learning outcomes and learners can move laterally between formal education into training and vice versa, as well as vertically from lower to higher levels of competency (Ensor, 2003).

However, as much as the NQF was part of the transition to democracy, it was also part of the transition to neoliberalism (Allais, 2007) and it is here that the contradiction lies. Neoliberalism, as Allais $(2003,2007)$ argues, suggests that the market is the most efficient means of delivering goods and services, and that the role of state should be reduced. Allais (2007) further points out that as governments become increasingly unwilling to intervene in the economy, education becomes the solution to the problems of unemployment. Education must then be relevant to the economy and an NQF which controls the registration of qualifications can ensure that only relevant and useful qualifications are offered.

A further consequence of a neoliberal approach is the increased need for quality assurance mechanisms, as the state must ensure that the money it does spend is well spent. Outcomesbased education, with its emphasis on specific outcomes against which to measure competence, becomes a means by which programmes can be evaluated. In these circumstances resources are allocated according to performance and are dependent on the degree to which specified criteria are fulfilled. In other words, as Smyth and Dow (1998) point out, the product rather than the process is evaluated and controlled. Increasingly, as learning is seen as an outcome, students are seen as consumers and teachers as producers.

Initially the National Qualifications Framework was built upon a unit standard methodology (Ensor, 2003). The idea was that all qualifications could be broken down into smaller creditbearing units each with its own learning outcomes. One credit was allocated for each 10 hours of learning. Learners could then study these units at different times and at different locations, and accumulate credits at their convenience.

Twelve National Standards Bodies (NSB), comprising a wide range of stakeholders, were established to develop the standards to be registered in each of 12 learning or organising fields. Each NSB then authorised sub-structures called Standards Generating Bodies (SGBs) to generate unit standards for the specific jobs fields within the organizing field. An SGB for Social Work was approved by SAQA in March 2001 and registered the following month 
(Lombard et al., 2003). To begin with, the SGB started generating unit standards, but it was later decided to move to a whole qualification to ensure "holistic, coherent learning and lessen the possibility of being too prescriptive in terms of curriculum design" (Lombard et al., 2003:7) and in fact Social Work was the first whole qualification to be registered. It is worth mentioning that South African universities had argued strongly that unit standards were inappropriate for higher education (Ensor, 2003). They had argued that standards setting and curriculum development were inextricably linked and that many important goals in higher education could not be reduced to an observable learning outcomes (Ensor, 2003). In addition, Kilfoil (2003) makes the point that OBE has not been applied consistently at universities anywhere in the world, because of its reductionist and technicist focus which values practice above theory.

In 2003 the Bachelor of Social Work (BSW) qualification was registered in the National Qualifications Framework (Lombard et al., 2003). In 2004 all providers of social work education were required to benchmark their existing programmes against the new minimum standards. At that stage each exit-level outcome (ELO) had been allocated a number of credit points relating to the number of hours that a learner should spend on learning and achieving that particular outcome. Thankfully, that degree of specification was later abandoned. The exercise was however useful for many social work programmes and alerted us to gaps in the curriculum. As a result, at my own university (UKZN) a new module focusing on critical social work and anti-oppressive practice was introduced and several modules were re-designed to incorporate a stronger emphasis on social policy.

By 2007 all providers of social work education had to implement the new learning programme which encompasses 27 exit-level outcomes (ELOs), each with a number of associated assessment criteria (AAC). In addition, they have to demonstrate how the critical cross-field outcomes (CCFOs) are related to each aspect of the programme. In 2008 the professional Board for Social Work held workshops with universities to discuss the quality assurance of the BSW programme and during 2009 all providers of social work education had to conduct these selfassessments in which they assessed the extent to which they have aligned their curricula with the ELOs as stipulated in BSW. This was in preparation for an audit of social work programmes which is set to take place in 2010 (SACSSP, 2009).

\section{OUTCOMES-BASED EDUCATION: AN OVERVIEW}

Outcomes-based education emerged in the USA in the 1960s and 1970s in response to some of the social concerns of the time, specifically the need to provide American citizens with the ability to regain technological superiority in the face of the Soviet Union's growing power (Hodge, 2007). In Australia and New Zealand OBE became the official policy for education in schools. OBE re-defined education in terms of what learners would know at end of their education. This involved a shift from objectives derived from textbooks or content to a focus on the desired changes in students' learning (King \& Evans, 1991).

Jansen (1998) and Berlach (2004) point out that outcomes-based education has its ideological roots in a number of theories and models such as Skinner's behavioural psychology, Bloom's idea of "mastery of learning", competency education, rationalism and technical rationality. In social work education competency-based education models gained popularity in the 1970s and writers such as Armitage and Clark (1975) argued strongly that the purpose of professional education was to teach effective practice behaviours. The social work educator should then 
clarify the skills to be mastered, develop appropriate teaching activities and develop a set of measures for determining whether the skills has been mastered (Larsen, 1980).

According to Killen and Hattingh (2004), OBE has four simple principles. These are:

- Clarity of focus: The education system must focus clearly on what outcome students should achieve;

- Designing back: The starting point for curriculum design is the outcome or end product and all teaching and learning activities, including assessment, must be aligned;

- High expectations: All learners are expected to achieve the outcomes;

- Expanded learning opportunities: Not all learners learn in the same way or at the same time and therefore multiple learning opportunities should be provided.

At first glance one cannot argue with these assumptions. Good educators are concerned with having clear expectations and ensuring that assessment is fair and linked to these expectations. Good educators do want students to succeed and will organise their classrooms and teaching practice to give students these opportunities. As Dykman (1994:37 cited in Berlach, 2004:2) stated, "At first, people tend to agree with the broad premises of outcomes-based education... The problems crop up in the details." In the remainder of this article I discuss some of these problems.

\section{CLARITY OF FOCUS AND "DESIGNING BACK": OUTCOMES AS THE ORGANISING FRAMEWORK FOR TEACHING AND LEARNING IN SOCIAL WORK}

Outcomes are what the learner knows and can do as a result of learning (Otter, 1992 in Allan, 1996). The assumption is that transparent, clear and measurable outcomes provide a better basis for selection of learning content and pedagogy than subject or discipline (Allais, 2007). Allais (2007) goes on to point out that outcomes are intended to have a clear meaning independent of the context of a learning programme and no area of knowledge is thus privileged. In fact, the only value is in the outcome, which could, in theory, be achieved by studying something else. In this section I will provide a number of examples to illustrate that outcomes as specified in the BSW are not a useful way to organise learning. Not only are they prescriptive, but they also preclude certain types of learning.

ELO 8 states that a person, having completed the BSW, will be able to: "Negotiate and use contracts during social work intervention." Three AAC are linked to this ELO. They are:

8.1 Contracts contain, as far as is reasonable and possible, mutually agreed upon principles, expectations, goals and procedures;

8.2 Contracts are used to guide practice with clients;

8.3 Contracts contain an exposition of possible results/consequences of breaching the mutually agreed upon principles, expectations, goals and procedures for both the practitioner and the client system.

A social work student who had worked as a paralegal assistant could, for instance, prove that he/she could draw up contract that complies with the AAC 8.1 and 8.3 and argue that he/she does not need to attend the social work classes that deal with this topic, nor do the associated assessment task. Alternatively, the lecturer could simply provide a template for the contract (teaching activity), insist that students study it (learning activity) and then reproduce it (assessment task). Important learning that should be associated with the use of contracts in 
social work practice is ignored. For example, the very word "contract" in social work is problematic (as is the implied threat of sanctions on AAC 8.3). Important aspects such as discerning when and what type of contracts (or service agreements) are appropriate in the different contexts of social work practice and exploring the theoretical consistency of social work constructs within social work theories are thus missed.

SAQA contends that while outcomes and assessment criteria are controlled at a macro-level, the learning programme (the what and the how of teaching) is left to the discretion of the educator (Luckett, 2000). This is not so. The fact that one thing is stated implies that another is not. For example, ELO1 states: "Develop and maintain professional social work relationships with client system" and there are four AACs, the first of which is: "1.1 Professional relationships are purposefully founded on knowledge of and insight into the nature of client systems and their dynamics". This emphasis on the relationship being founded on knowledge of client systems means that theories about client systems must be covered. While systems theory provides useful concepts for conceptualising how systems function and interact and how one system can affect another, it has little to say about the nature of professional relationships (Wakefield, 1996). None of the AACs deal with the elements of a professional relationship or the skills that are useful in building the relationship. Our curriculum would be poorer for not examining what Rogers (1980) had to say about the importance of the helping relationship, and for not analysing how words such as "relationship", "partnership", and "working alliance" might change the nature of the helping process. Students should be able to critique what different theories say about relationship and to discuss the different circumstances in which different types of relationships would be appropriate. However, if the outcome does not require this knowledge, why should it be included in the curriculum?

A further example is AAC12.5, which states; "The critical role played by social auxiliary work within the social welfare context is substantially motivated". This statement makes a value judgement about social auxiliary work and assumes that social auxiliary work does play a critical role in the social welfare field. The reality is that there are many areas in which social auxiliary work is absent and which it does not play a critical role.

AAC 22.3, which states: "The types and theoretical underpinnings of modern management systems are described and critiqued", is an example of how an outcome determines what is included/excluded in the curriculum - only modern (not old fashioned?) management systems must be taught and learned. Of course this raises further questions: What are modern management systems and at what point would a modern management system not be modern any longer?

\section{HIGH EXPECTATIONS AND EXPANDED LEARNING OPPORTUNITIES: CHALLENGES OF ASSESSMENT}

In an outcome-based educational system all learners are expected to achieve the outcomes and because they are all unique and learn in different ways, multiple learning and assessment opportunities must be provided. However, there are several problems with this premise. One has to do with the large classes and diminishing resources at university and the other has to do with the way in which teaching and learning at universities is organised.

At the University of KwaZulu-Natal, for example, each Social Work module is worth 16 credits (or multiple thereof) and is delivered over a 13-week period. One lecturer has a class of upwards of 150 students. Let's imagine that there are four assignments designed to assess different aspects of the ELO. Each needs to be marked and given back to students within two 
weeks for effective feedback and to provide sufficient time for the student to improve. Each assignment takes approximately 30 minutes to mark. This means that the lecturer will spend about 300 hours marking, that is 7.5 weeks of the 13 weeks! There is simply no time for students to re-submit assessment tasks until they can achieve the outcome. The reality is that the education system is time based, and teaching and learning take place within fixed, predetermined time frames. In a web-based article, Spady (n.d.), one of foremost proponents of OBE, in examining the difficulties of implementing OBE, makes the point that trying to force outcomes into a time-based system is like trying to force "soft, large round pegs into rigid, small, square holes"! An outcomes-based assessment system requires a total overhaul of the structure and management of education institutions.

Outcomes-based assessment, as Bozalek (2009) points out, is supposed to be respectful of learners and focus on their strengths rather than weaknesses. Suggesting that students are "not yet competent" rather than "failing" sounds nice, but again does not fit with the reality of the way in which university study is organised. Students have a certain amount of time in which to master the course content and if they do not they unfortunately fail. Good educators know that this is not a reflection on the worth of the student as a person and can communicate this to students. They do not need to move to outcomes-based system in order to be respectful of students.

It does not make sense to have one assessment task per AAC and inevitably one task will assess more than one AAC. The problem with this is that is it possible that students may pass overall but still have not shown evidence of achieving one or more aspects of the ELO. Marks are aggregated and it would not be fair to make a student repeat a module because they had not passed one aspect of that module. At the same time, it would be an administrative nightmare to keep track of which AAC a particular student still needed to achieve and to provide the opportunity to do that as part of another module.

Outcomes are supposed to be clear and measurable, but some of the assessment criteria in the BSW are not measurable. For example, AAC 1.4 states: "Enabling environments are created for clients to achieve their full potential". Expecting student social workers to demonstrate their ability to do this is simply absurd as even experienced social workers do not have the power to influence the environment so totally. The best we can do is help students to be aware of the challenges of creating enabling environments, to understand the role of other stakeholders, and to help them develop the skills that will enable them to work towards this noble ideal.

The emphasis on practice demonstrating achievement of objectives is also highly problematic within the current situation of the shortage of social workers and the challenges that this poses both for education and practice. In social work education we are being expected to educate more students, resulting in larger classes, and this inevitably results in more pressures on social work organisations to provide placements and supervision for students. Many social work organisations cannot cope with additional work, thus setting in motion a vicious cycle in which neither the university nor the field can provide adequate learning opportunities, practice supervision and competent assessment.

In some cases it may be simply impossible for a student to demonstrate certain learning. AAC 4.2 insists that: "Referrals to appropriate resources are made according to agreed upon methods of referral". This means that a student must be given an opportunity (learning activity) to make a referral in order to demonstrate achievement of this outcome. In some settings referrals may be the order of the day, but in others students will have little or no opportunity to demonstrate 
this. We cannot artificially create opportunities in social work - good social work practice responds to the needs of the service user in the here and now. If the service user does not need to be referred, so be it. Students could, however, be required to describe how good referrals should be made, but this is not what the AAC demands.

\section{RECOMMENDATIONS AND CONCLUSION}

Writing in the context of the Australian school system, Smyth and Dow (1998) make the point that educators are being increasingly controlled by outsiders through surveillance and performance management policies. The role of the South African Council for Social Service Professions in protecting and promoting the profession of social work is a statutory one and, as such, it has a role in ensuring that social work education is not only of a high standard but also relevant to the needs of the profession. It is important to safeguard our profession and to ensure that social work students are well prepared for the challenges facing them in reality. The BSW and its registration on the NQF was, I believe, an attempt to do just this. However, as I have argued in this article, the outcomes-based approach to social work education is problematic and will not automatically lead to improved standards.

Furthermore, the SACSSP needs to guard against eroding the academic freedom of universities. Academic freedom relates to the freedom to teach and research without outside interference (Malherbe \& Berkhout, 2001). As I have argued in this article, the ELOs and AAC do control what we teach and how we assess. The NQF and the BSW with its outcomes-based approach is a threat to academic freedom which we should not take lightly.

My suggestion is that the number of ELOs be reduced (for example, contracts can be included as part of the social work intervention and do not need a separate category) and collapsed into learning areas. These learning areas have already been identified in the self-assessment exercise - policy and legislation; intervention; inequality and social inclusion; management, administration and supervision; and research - and provide an overarching framework for ensuring that all important aspects be included in the curriculum. Associated assessment criteria should be scrapped completely.

The SACSSP could continue to exercise its oversight role by requiring each university to develop its own detailed curriculum statement which would include a detailed teaching and learning philosophy and the assessment policy. Universities should be required, in the interests of accountability and transparency, to justify their approach in terms of their student body and local circumstances, but should have the freedom to choose what and how to teach and assess.

The development of the BSW was no doubt well intentioned, but social work cannot be reduced to a technical skill or set of skills. As I have argued in this article, the prescriptive nature of the learning outcomes and associated assessment criteria severely limit learning opportunities. The goal of learning in OBE is to demonstrate the achievement of specified outcomes. How then are we to foster what Eccelstone (1998:29) refers to as "broader notions" of student centredness such as intellectual independence, the ability to think creatively and critically, and to understand what is happening in the local and wider world? Social work as a discipline and as a profession is full of ambiguities and needs creative and critical thinkers who will have the intellectual depth to analyse current policies and practices, and develop new and better ways of solving the social problems of our time. If social work students merely have to demonstrate the range of competencies as presently constituted in the BSW, the danger exists that social work will become a technical, rational activity devoid of any depth of thought and unable to move beyond conventional insights and wisdom. 


\section{REFERENCES}

ALLAIS, S.M. 2003. The National Qualifications Framework in South Africa: a democratic project trapped in a neo-liberal paradigm? Journal of Education and Work, 16(3):305-324.

ALLAIS, S.M. 2007. Education service delivery: the disastrous case of outcomes-based qualifications frameworks. Progress in Development Studies, 7(1):65-78.

ALLAN, J. 1996. Learning outcomes in higher education. Studies in Higher Education, 21(1):93-108.

ARMITAGE, A. \& CLARK, F.W. 1975. Design issues in the performance-based curriculum. Journal of Education in Social Work, 11(1):22-29.

BERLACH, R.G. 2004. Outcomes-based education and the death of knowledge. Paper presented at The Australian Association for Research in Education, The University of Melbourne, Victoria, Australia. [Online] Available: http://www.aare.edu.au/04pap/ ber04768.pdf [Accessed: 02/10/2009].

BLOCH, G. 2009. The toxic mix: what's wrong with South African schools and how to fix it. Cape Town: Tafelberg.

BOZALEK, V. 2009. Outcomes-based assessment: necessary evil or transformative potential? Social Work/Maatskaplike Werk, 45(1):91-110.

CHISHOLM, L. 2007. Diffusion of the National Qualifications Framework and outcomesbased education in southern and eastern Africa. Comparative Education, 43(2):295-309.

ECCLESTONE, K. 1999. Empowering or ensnaring? The implications of outcomes based assessment in higher education. Higher Education Quarterly, 53(1):29-48.

ENSOR, P. 2003. The National Qualifications Framework and higher education in South Africa: some epistemological issues. Journal of Education and Work, 16(3):325-346.

HESA (Higher Education South Africa). 2009. Briefing on the National Benching Test Project to the Parliamentary Monitoring Group on $19^{\text {th }}$ August 2009. [Online] Available: http://www.pmg.org.za/report/20090819-national-benchmark-tests-project-standards-nationalexamination-asses [Accessed: 01/10/2009].

HODGE, S. 2007. The origins of competency based learning. Australian Journal of Adult Learning, 47(2):179-209.

JANSEN, J.D. 1998. Curriculum reform in South Africa: A critical analysis of outcomes based education. Cambridge Journal of Education, 28(3):321-331.

KILFOIL, W.R. 2003. Implementing national qualifications framework policy. South African Journal of Higher Education, 17(3):54-59.

KILLEN, R. \& HATTINGH, S.A. 2004. A theoretical framework for measuring the quality of student learning in outcomes-based education. South African Journal of Higher Education, 18(1):72-86.

KING, J.A. \& EVANS, K.M. 1991. Can we achieve outcomes based education? Educational Leadership, October:73-75.

LARSEN, J. 1980. Competency-based and task-centred practicum instruction. Journal of Education for Social Work, 16(1):87-94. 
LOMBARD, A., GROBBELAAR, M. \& PRUIS, S. 2003. Standards for social work qualifications in South Africa. Social Work/Maatskaplike Werk, 39(1):1-17.

LUCKETT, K. 2000. Negotiating a way onto the NQF: a humanities perspective. South African Journal of Higher Education, 14(1):62-74.

LUGG, R. (n.d.). Going for growth or development? Fractured state and ruptured policy: The National Qualifications Framework in South Africa. NORRAG (Network for Policy Research, Review and Advice on Education and Training). [Online] Available: http://www.norrag.org/db_read_artcile.php?id=1144 [Accessed: 01/10/2009].

MALHERBE, R. \& BERKHOUT, S. 2001. The national qualifications framework and the unconstitutional limitation of academic freedom. South African Journal of Higher Education, 15(2):62-73.

REPUBLIC OF SOUTH AFRICA. 1995. South African Qualifications Authority Act, No 58 of 1995. Government Gazette No 1521. Pretoria: Government Printer.

REPUBLIC OF SOUTH AFRICA. 2008. National Qualifications Framework Act, No 67 of 2008. Government Gazette No 31909. Pretoria: Government Printer.

ROGERS, C.R. 1980. A way of being. Boston: Houghton-Mifflin.

SACSSP (South African Council for Social Service Professions). 2009. Quality assurance of the BSW programme. Official newsletter, 1(1):9. [Online] Available: www.sacpps.co.za. [Accessed: 12/04/2010].

SMYTH, J. \& DOW, A. 1998. What's wrong with outcomes? Spotter planes, action plans, and the steerage of the educational workplace. British Journal of Sociology of Education, 19(3):291-303.

SPADY, W. (n.d.) Outcomes based education - The dilemma of defining outcomes based education, objective based education as a reform ideal. [Online] Available: http://education.stateuniversity.com/pages/2304/Outcomes-Based-Education.html. [Accessed: 01/12/2009].

WAKEFIELD, J. 1996. Does social work need the eco-systems perspective? Part 1. Is the perspective clinically useful. The Social Service Review, 70(1):1-32.

Dr Barbara Simpson, School of Social Work and Community Development, University of KwaZulu-Natal, Durban, South Africa. 